\title{
Pneumosinus dilatans associated with infantile cerebral palsy and nasal polyposis: Case report
}

\author{
Juan Antonio Lugo-Machado ${ }^{\circledR}$, Luis Manuel Justo Enriquez ${ }^{2} \mathbb{D}$, Martha Lucía Gutiérrez \\ Pérez $^{3}{ }^{(0)}$, Natalia Barreto Niño ${ }^{3}$, David Fernando Acevedo Contreras ${ }^{3}$, Luis Alfonso \\ Paredes Bastos ${ }^{3}$, Fernanda Verena Barragan Marquez', Lorenz Lizarraga Lizarraga ${ }^{1}$, \\ Martha Jeaneth Jimenez Rodriguez ${ }^{1}$, Dalia Iveth Yocupicio Hernández ${ }^{4} \mathbb{B}$ \\ ${ }^{1}$ Otorhinlaryngology Service, "Lic. Luis Donaldo Colosio Murrieta" Specialty Hospital No. 2, Mexican Institute of \\ Social Security, Ciudad Obregón, Sonora, Mexico \\ ${ }^{2}$ Family Medicine Medical Hospital No. 1, Mexican Institute of Social Security, Ciudad Obregón, Sonora, Mexico \\ ${ }^{3}$ School of Medicine, El Bosque University, Bogotá, Colombia \\ ${ }^{4}$ Social Service, University of Sonora, Campus Cajeme, Ciudad Obregón, Sonora, Mexico
}

\section{ABSTRACT}

Pneumosinus dilatans is a rare disease characterized by air-filled expansion of a paranasal sinus. Approximately 134 cases are reported in the literature, but not only one associated with infantile cerebral palsy (ICP) and nasal polyposis. We herein present this case report aimed to further characterize this uncommon condition: a 28-year-old female diagnosed with infantile cerebral palsy and nasal polyposis, in whom the cranio-facial CT scan revealed the association of a pneumosinus dilatans involving the frontal sinus. The patient is currently undergoing a protocol for endoscopic surgery of the nose and paranasal sinuses.

KEYWORDS: pneumosinus dilatans, polyposis, infantile cerebral palsy.

\section{INTRODUCTION}

Pneumosinus dilatans (PD) is a rare disease characterized by pathologic hyperaeration of one or more paranasal air sinuses ${ }^{1-3}$. The sinus appears filled with air, without radiological evidence of localized bone destruction, mucous membrane thickening or hyperostosis. Facial deformity can be a sign for this pathology. The first who described the disease was Meyes WP in 1898 under the name of Pneumatocoele ${ }^{4}$. Then, in 1918, Benjamin CE assigned the name of Pneumosinus Dilatans ${ }^{5}$.

In most cases the frontal sinus is involved ${ }^{6}$. However, the maxillary sinus, ethmoidal cells, and the sphenoid sinus can also be affected ${ }^{7}$.

Pneumosinus dilatans has been usually found when diagnosing another cranio-facial or cerebral pathology. Although associations with nasal polyposis, intracranial tumors, unusual bony hyperostosis of the cranio-facial skeleton and hypovitaminosis D have been reported ${ }^{8-10}$, a case of PD associated with infantile cerebral palsy and nasal polyposis has never been published in the medical literature.

\section{CASE REPORT}

This is a 28-year-old patient with a history of infantile cerebral palsy due to neonatal hypoxia, who was referred to the Otolaryngology Service of our hospital for chronic rhinosinusitis with nasal polyps with more than 4 years of evolution. On physical examination, we found an uncooperative 


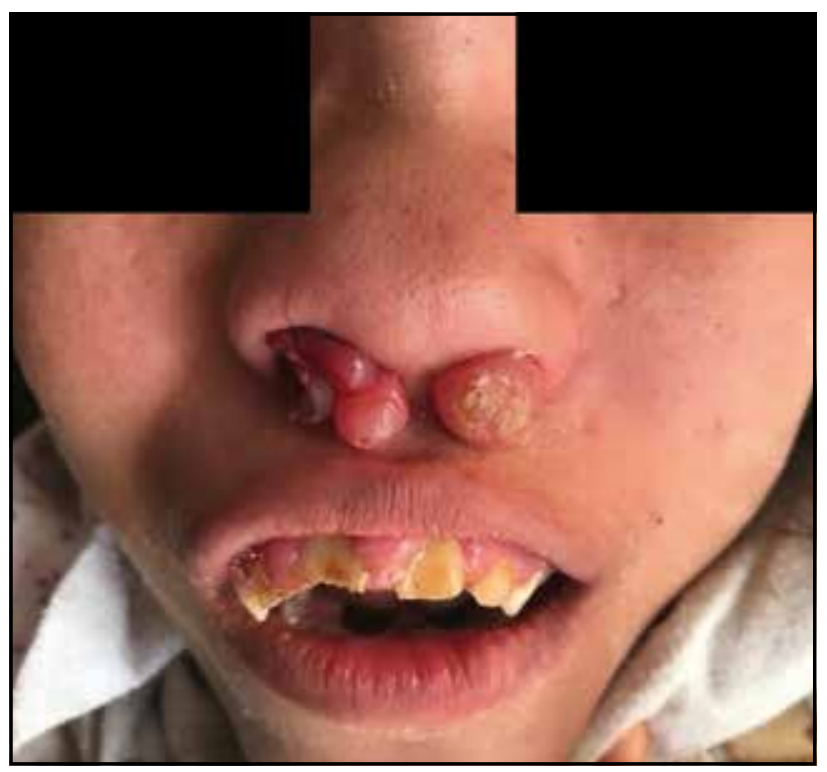

Figure 1. Clinical examination of our patient - pale pink tumors protruding from both nostrils.

bedridden patient with pale pink tumors that protruded from both nostrils (Figure 1).

The paranasal sinus tomography identified an opacification of all the nasal and paranasal cavities due to soft tissue density lesions (Figure 2), and a widely dilated frontal sinus with soft tissues density content A three-dimensional reconstruction tomography (3D reconstruction CT scan) was also performed, and the image showed a widely dilated

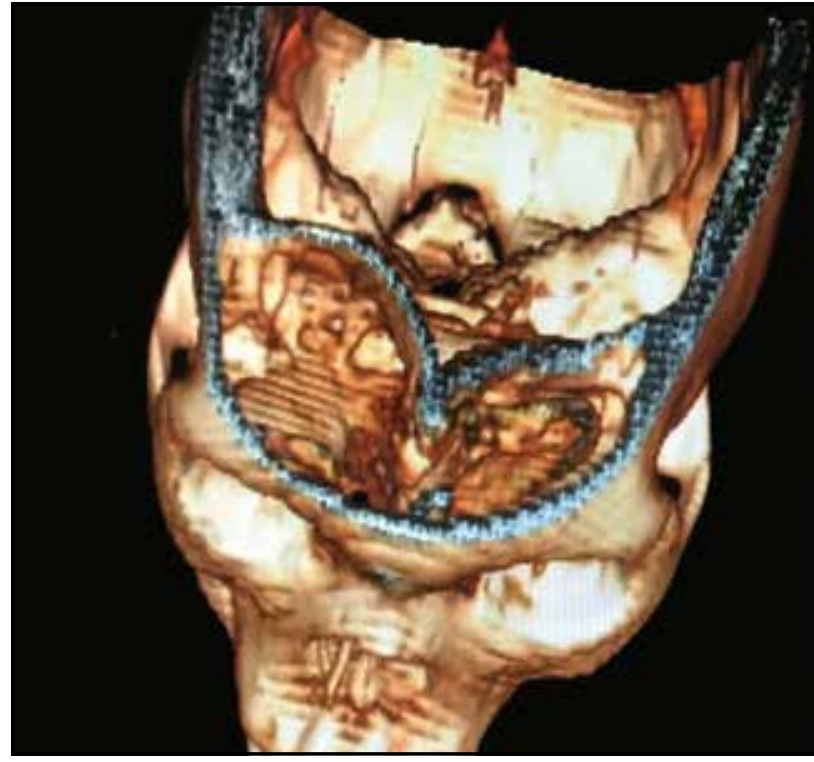

Figure 3. 3D reconstruction CT scan, showing the expansion of the sinus.

frontal sinus (Figure 3).

The imagistic evaluation was completed with a cranio-facial MRI. The examination confirmed the soft tissue lesions at the level of nasal cavities and paranasal sinus. The T2 sequence excluded the intracranial extension of the pathologic content (Figure 4).

We decided to take a biopsy of the intranasal tumor. The histopathologic examination identi-
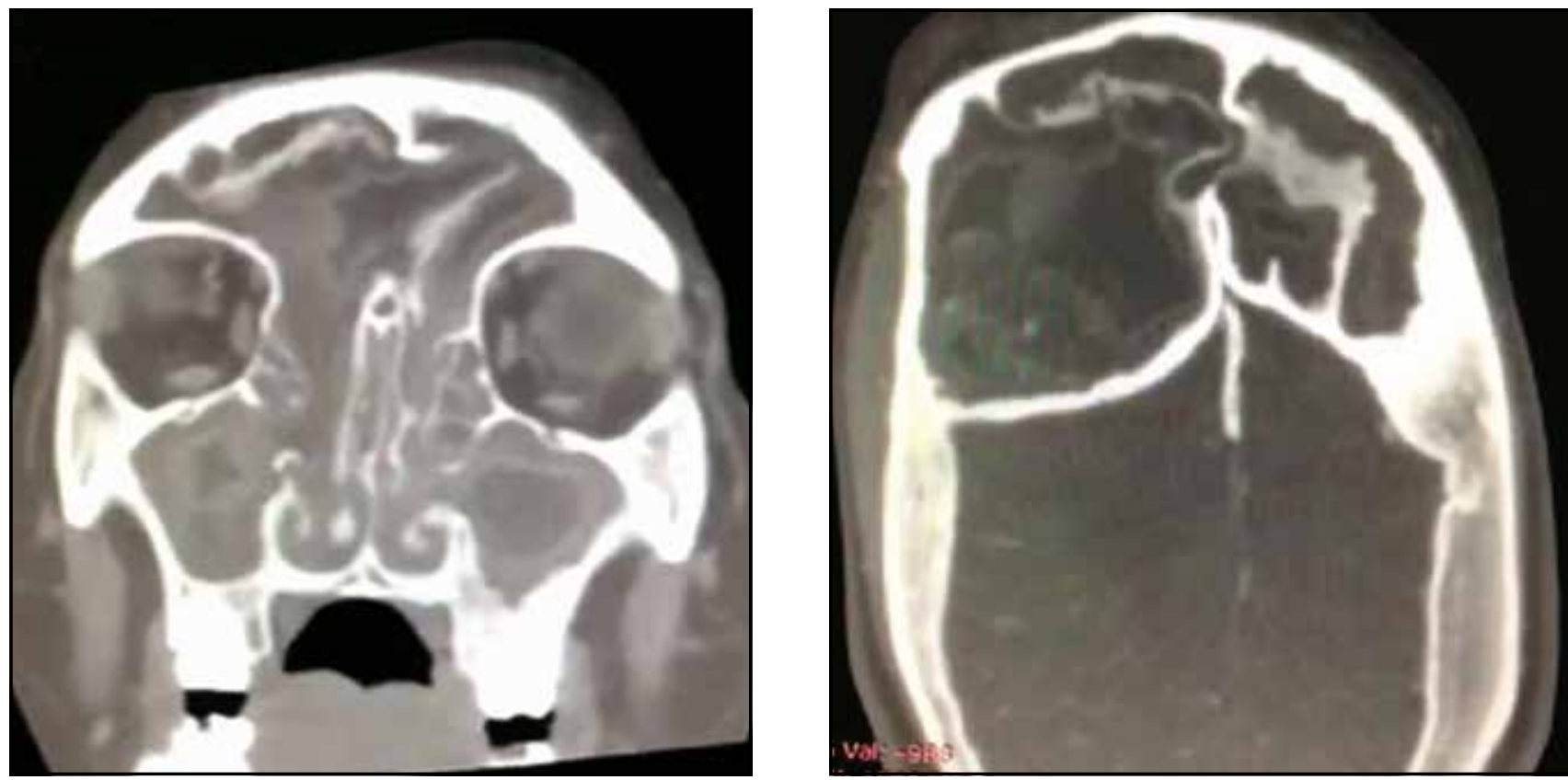

Figure 2. Cranio-facial CT scan: coronal slice - opacification of all nasal and paranasal cavities due to soft tissue density lesions; axial slice - markedly expanded frontal sinus, filled with mucous membrane thickening and secretions due to nasal polyposis. 


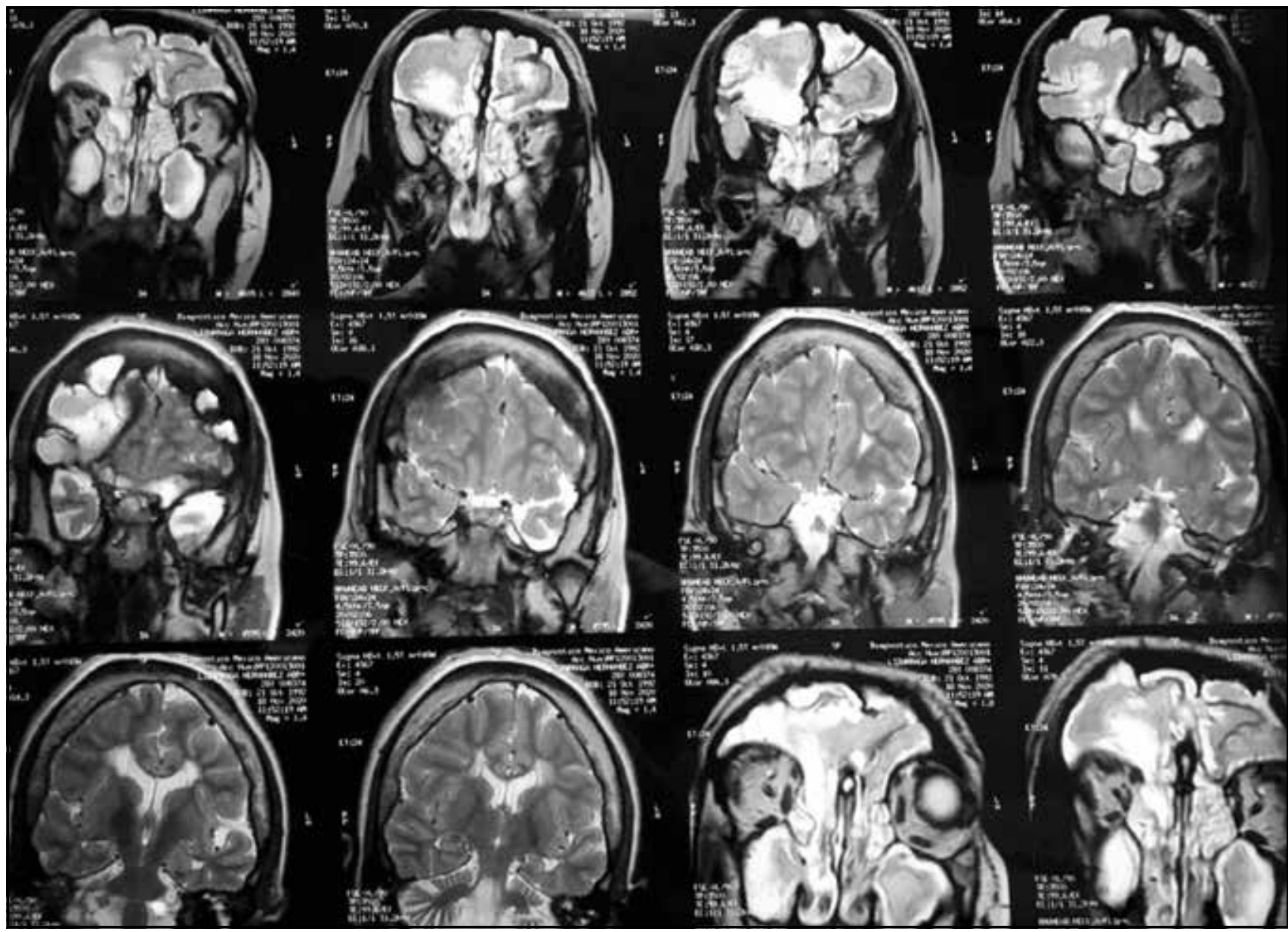

Figure 4. The nuclear magnetic resonance image in $\mathrm{T} 2$ sequence shows the absence of intracranial involvement.

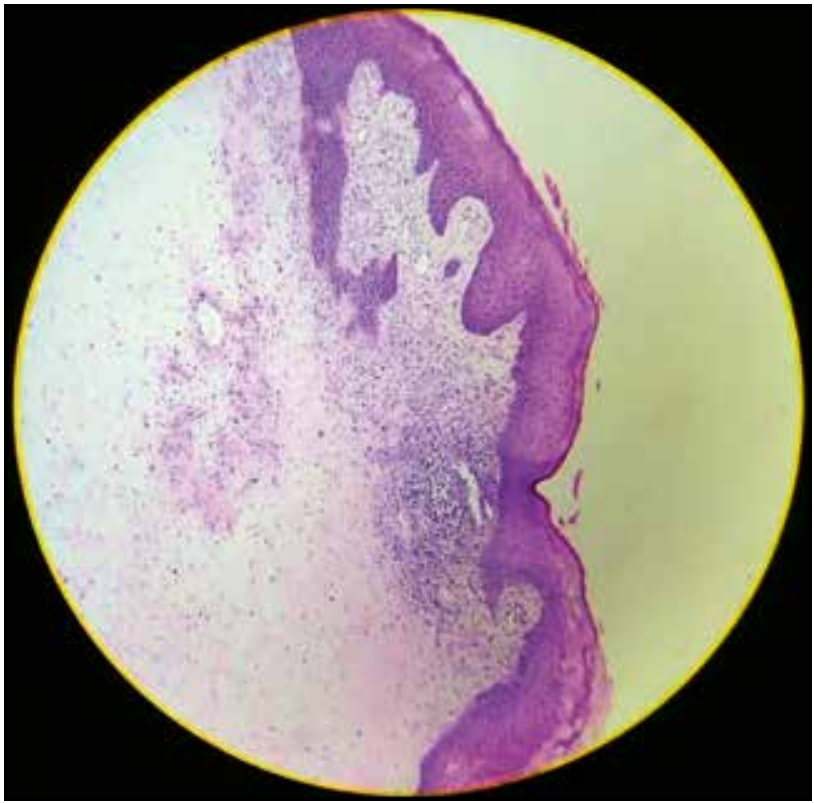

Figure 5. Histological section of the nasal polyp, showing the typical pattern of the polyp cells, inflammatory polyp with intense infiltrate of inflammatory cells in the stroma. fied a typical pattern of respiratory epithelium, edematous and lax stroma with hyperplastic mucous glands, inflammatory infiltrate with some eosinophils, neutrophils and mast cells (Figure 5), specific for inflammatory nasal polyposis.

Given the special conditions of the patient, we decided to perform an endoscopic surgery procedure in order to permeate the nasal cavity and improve nasal breathing. A bilateral nasal polypectomy was performed with the microdebrider with the permeabilization of both nasal fossae. This procedure allowed us to open the right frontonasal recess with the exit of thick white secretions (Figure 6). The polypoid formations from the left frontonasal recess were ablated with the aspiration of some mucous, viscous secretions from the right frontal sinus. Due to an important bleeding, we decided to interrupt the procedure and to complete it in a second stage, which was performed 6 months after this last intervention. The postoperative evolution and follow-up were within normal limits. 


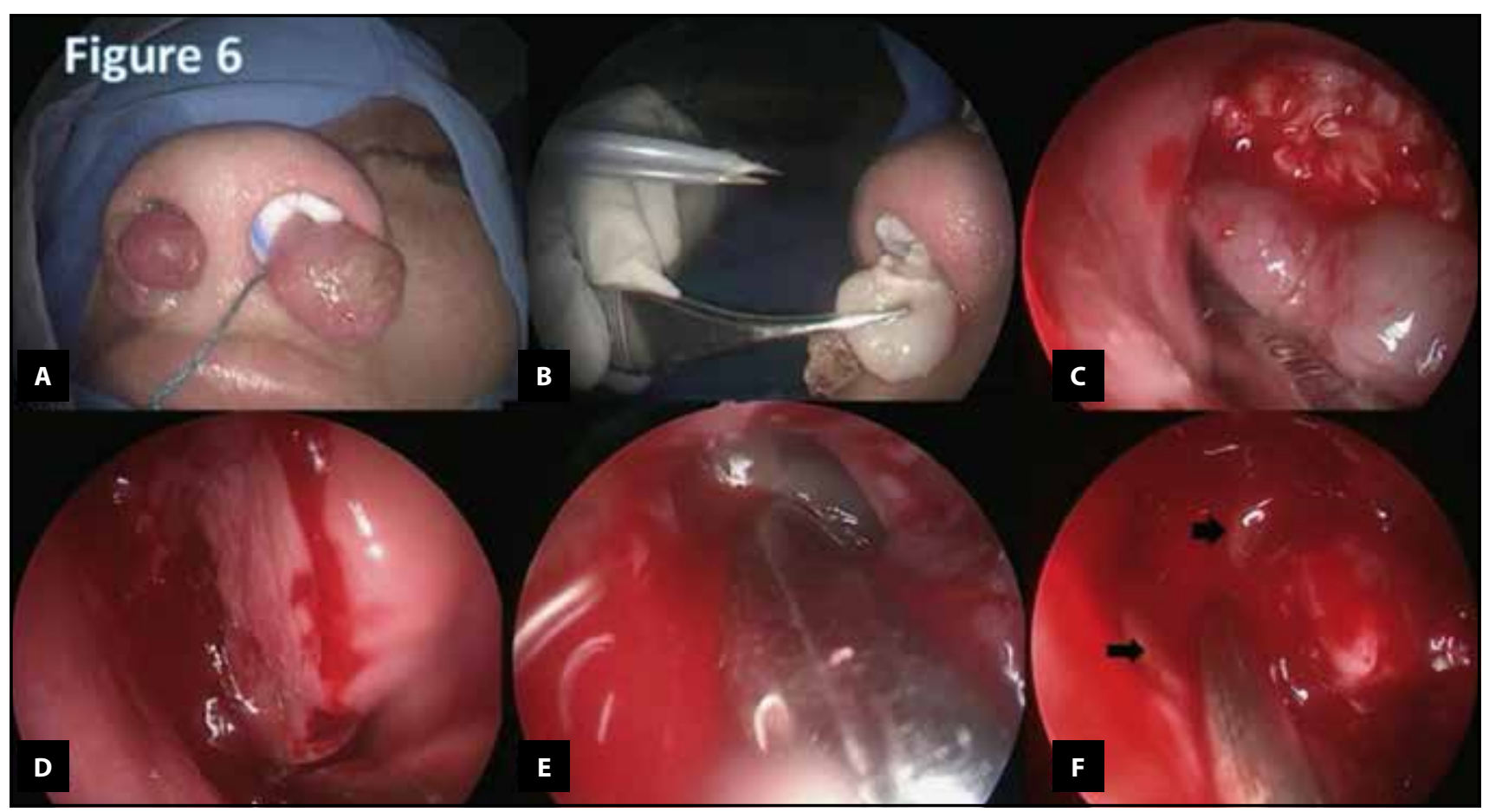

Figure 6. Series of images during surgery: $\mathbf{A}$ and $\mathbf{B}$. the preoperative external appearance; $\mathbf{C}$. resection with a microdebrider in the nasal cavity; D. permeabilized nasal cavity; $\mathbf{E}$ and F. permeabilization of the recess of the right frontal sinus and the exit of thick white material is evident, indicated by the black arrow.

\section{DISCUSSIONS}

This entity is believed to be a rare disorder, but the true incidence of pneumosinus dilatans remains largely unknown ${ }^{11}$. According to Dr. Joseph A. Ricci $^{8}$ as of 2017 , there have been 134 cases reported since the original case description in 1898.

The etiology of PD is still unknown. Various researchers have proposed various theories ${ }^{8,12-15}$, but none have substantial evidence to support their validity and the available data have never been comprehensively summarized in one place. Several theories have been presented in the literature. A frequently involved mechanism seems to be the "ball-valve" or one-way valve mechanism which implies the existence of an obstruction of the frontonasal duct leading to sinus air trapping or a disruption of the cellular milieu due to a fibro-osseous process ${ }^{8,9,13}$. A spontaneous drainage of a frontal mucocele, trauma, hormonal dysregulation, a gas-forming microorganism, the osteoblastic and osteoclastic activity, or congenital defects have also been proposed $^{12-15}$. Unfortunately, the hormonal involvement is a less substantiated theory, while there is no data to support the bacterial process.

As a result of the scarcity of scientific evidence for the different theories proposed on the etiology, patients with pneumosinus dilatans have not been evaluated or treated in a standardized way. Also, the presence of pneumosinus dilatans and concomitant pathologies is scarcely published. The few cases found in the literature show an association of PD with meningioma, nasal polyposis, meningocele, fibro-osseous disease, Klippel-Trenaunay-Weber syndrome, MelnickNeedles syndrome, brain atrophy ${ }^{6,13,16-20}$.

In our case, pseudosinus dilatans was associated with infantile cerebral palsy and chronic rhinosinusitis with nasal polyposis, being the first case reported in the literature. The finding of infantile cerebral palsy with frontal lobe cortical atrophy could suppose the hypothesis that the great dilation of the frontal sinus was favoured by the low intracranial resistance in this particular patient. However, this is only a presumption with no robust scientific basis.

The diagnosis of pseudosinus dilatans is usually made on clinical symptoms and is confirmed by the imaging characteristics. The clinical symptoms are directly related to the displacement of the surrounding structures: prominence of the supraorbital ridge, headache, sinus pressure, diplopia, anosmia. According to Thimmasettaiah et al., from the clinical point of view, there can be described two types of PD: one form with early signs and symptoms related to the increase in the sinus pressure, and one form in which the first symptom is frontal deformity, the other symptoms being absent or with late onset ${ }^{21}$.

The imaging modality of choice is the craniofacial computerized topography (CT scan), imaging clinching the diagnosis ${ }^{15}$.

Correct diagnosis is of great importance in choosing the best surgical approach. The goal of PD treat- 
ment is to restore the normal function and shape of the affected paranasal sinus. Different surgical approaches are described in the literature: craniofacial approach, with remodelling and repair of the frontal bulge with alloplastic material that can lead to a high incidence of local complications; reduction of the anterior wall of the frontal sinus without obliterating the cavity with unsatisfactory aesthetic results; removal of the anterior wall of the frontal sinus and its replacement by bone fixed using miniplates or with a titanium mesh plate ${ }^{13,21-25}$.

\section{CONCLUSIONS}

Our case represents a very unique situation and possibly like this, very few reported in the literature. The challenges in such cases can be various. Starting from the values of the hemodynamic function and going up to the anatomic and surgical variants discovered intraoperatively, all involve the risk of skull base damage. For this reason, we believe that excellent communication between the members of the operating team is essential.

In the present patient, it is probable that a series of incidents that characterize the case as extremely rare have been combined. Finding a case with infantile cerebral palsy, nasal polyposis and pneumosinus dilatans is an extremely strange association and not reported in the national and international literature up to the moment.

Conflict of interest: All authors declare that there are no conflicts of interest in this work.

Contribution of authors: All authors have equally contributed to this work.

Funding statement: None.

\section{REFERENCES}

1. Rosés Sáiz R, Font Julià E, García Ortega F, Piñero Cutillas C. Progressive proptosis secondary to pneumosinus dilatans of the ethmoidal sinus in a pediatric patient. Orbit. 2021;40(2):162-6. DOI: 10.1080/01676830.2020.1757125. Epub 2020 Apr 22.

2. Lee JS, Park YS, Know JT, Suk JS. Spontaneous pneumocephalus associated eith pneumosinus dilatans. J Korean Neurosurg Soc. 2010;47(5):395-8. DOI: $10.3340 /$ jkns.2010.47.5.395. Epub 2010 May 31.

3. Gitto L, Serinelli S. Pneumosinus Dilatans frontalis: a case of incidental autopsy diagnosis. Forensic Sci Med Pathol. 2019;15(4):6468. DOI: 10.1007/s12024-019-00120-7. Epub 2019 Jun 3.

4. Meyes WP. Mittheilung eines Falles vermatchlicher Pneumatocoele des Sinus frontalis. Montatsschr Ohrenheilkd. 1898;32:467-9.
5. Benjamins CE. Pneumo-sinus frontalis dilatans. Acta Otolaryngologica. 1918;1 (1):412-22.

6. Saravanan K, Saravanappa N. Pneumosinus dilatans of the frontal sinus. The Internet Journal of Radiology. 2007;8(1):1-3.

7. De Riu G, Bay A, Tullio A. Pneumosinus dilatans frontalis: a case report. Ear Nose Throat J. 2005;84(12):796-9.

8. Ricci JA. Pneumosinus dilatans: over 100 years without an etiology. J Oral Maxillofac Surg. 2017;75(7):1519-26. DOI: 10.1016/j.joms.2017.02.010.

9. Malinvaud D, Halimi P, Bonfils P. Pneumosinus dilatans associated with nasal polyposis. B-ENT. 2011;7(4):283-7.

10. Aryan S, Thakar S, Jagannatha AT, Channegowda C, Rao AS, Hegde AS. Pneumosinus dilatans of the spheno-ethmoidal complex associated with hypovitaminosis D causing bilateral optic canal stenosis. Childs Nerv Syst. 2017;33(6):1005-8. DOI: 10.1007/ s00381-017-3373-6. Epub 2017 Mar 13.

11. Kahler O. Etiology of pneumatocele of the frontal sinus. Z Laryngol Rhinol Otol. 1950;29(8):363-70.

12. Benedikt RA, Brown DC, Roth MK, Geyer CA, Ghaed VN. Spontaneous drainage of an etmoidal mucocele: a possible cause of penumosinus dilatans. Am J Neuroradiol. 1991;12(4):729-31.

13. Bouguila J, Ben Rejeb M, Omezzine M, Mani R, Khochtali H. Pneumosinus dilatans: rare cause of slowly changing frontal contours. Aesthet Surg J. 2015;35(3) :NP47-53. DOI: 10.1093/asj/sju045

14. Nowlin TP 4th, Hall DJ, Purdom EB, Holtel MR. Pneumosinus dilatans. Ear Nose Throat J. 2007;86(5):290-1.

15. Walker JL, Jones NS. Pneumosinus dilatans of the frontal sinuses: two cases and a discussion of its aetiology. J Laryngol Otol. 2002;116(5):382-5. DOI: 10.1258/0022215021910852.

16. Lloyd GA. Orbital pneumosinus dilatans. Clin Radiol. 1985;36(4):381-6. DOI: 10.1016/s0009-9260(85) 80308-1.

17. Scholsem M, Collignon F, Deprez M, Martin D. Spontaneous pneumocephalus caused by the association of pneumosinus dilatans and meningioma. Case illustration. J Neurosurg. 2006;105(6):934. DOI: 10.3171/jns.2006.105.6.934.

18. Tojima I, Kikuoka H, Ogawa T, Shimizu T. Severely infected pneumoceles of the frontal sinus in patients with mental retardation and brain atrophy treated by endoscopic sinus surgery. Auris Nasus Larynx. 2018;45(2):362-6. DOI: 10.1016/j.anl.2017.04.007.

19. Miller NR, Golnik KC, Zeidman SM, North RB. Pneumosinus dilatans: a sign of intracranial meningioma. Surg Neurol. 1996;46(5):471-4. DOI: 10.1016/s0090-3019(96)00032-8.

20. Stretch JR, Poole MD. Pneumosinus dilatans as the aetiology of progressive bilateral blindness. BR J Plast Surg. 1992;45 (6):469-73. DOI: $10.1016 / 007-1226(92) 90212-\mathrm{g}$.

21. Thinnasettaiah NB, Chandrappa RG, Sukumari S. Pneumosinus dilatans frontalis: a case report. Translational Biomedicine. 2014;5(1):1-5. DOI:10.3823/445.

22. Prott W. Pneumosinus dilatans der stirnhole. Laryngol Rhinol Otol. 1977;56(3):277-82.

23. Urken ML, Som PM, Lawson W, Edelstein D, Weber AL, Biller HF. Abnormally large frontal sinus. II. Nomenclature, pathology, and symptoms. Laryngoscope. 1987;97(5):606-11.

24. Pospisil OA, Balmer MC. Pneumosinus dilatans. Br J Oral Maxillofac Surg. 1988;26(5):375-80.

25. Rehman KU, Johnston C, Monaghan A, Dover S. Management of the giant frontal sinus - a simple method to improve cosmesis. $\mathrm{Br}$ J Oral Maxillofac Surg. 2009;47(1):54-5. DOI: $10.1016 / \mathrm{j}$. bjoms.2008.04.004. 